\title{
La privación de las exequias eclesiásticas en el Código de Derecho Canónico de $1983^{1}$
}

\author{
Deprivation of ecclesiastical funeral in the Code of Canon \\ Law of 1983
}

Recibido: 14 de junio de 2014 - Revisado: 09 de septiembre de 2014 - Aceptado: 19 de marzo de 2015

Kryspin Dubiel ${ }^{2}$

\section{Resumen}

El artículo presenta la legislación canónica sobre la sepultura eclesiástica. Expone las disposiciones canónicas del hecho de la muerte cristiana, haciendo alusión también a las litúrgicas. La tesis se orientó a comparar la normativa incluida en los dos códigos de derecho canónico. El presente documento se refiere particularmente a los casos en los que la iglesia concede o niega la sepultura eclesiástica con especial mención al Codex Iuris Canonici de 1983. Se tomó en consideración la legislación emanada después del código de 1917, la cual influyó en la conformación de la actual reglamentación. El tema no ha sido agotado, quedan algunas cuestiones pastorales relativas al caso de los familiares, quienes deben afrontar la situación cuando la iglesia priva de la concesión de las exequias a su pariente difunto.

\section{Palabras clave}

Sepultura eclesiástica, muerte cristiana, cremación.

\begin{abstract}
The article presents the canonical legislation about ecclesiastical burial. It exposes the canonical provisions concerning the fact of a christian death, referring also to the liturgical ones. The thesis was aimed at comparing the rules contained in the two codes of canon law. This document refers particularly to cases in which the church grants or denies the ecclesiastical burial with special reference to 1983 Code of Canon Law. It was taken into account the legislation issued after the code of 1917, which influenced the formation of the current regulation. The issue has not been exhausted; there are some pastoral issues conceding the relatives who must face a situation when the church deprives the funeral to their deceased relative.
\end{abstract}

\section{Keywords}

Ecclesiastical burial, Christian death, cremation.
${ }^{1}$ El artículo pertenece a una investigación jurídico-canónica orientada por el decano de la Escuela de Filosofía y Humanidades, de la Universidad Sergio Arboleda, concerniente a la sepultura eclesiástica, y analizada desde los aspectos jurídico y litúrgico; como también, está en relación con la tesis doctoral: "La privación de la sepultura eclesiástica en los códigos de derecho canónico de 1917 y de 1983", defendida en el 2003 por monseñor Kryspin Dubiel ante la Pontificia Universidad Lateranense (Roma) y publicada en el 2004.

2 Doctor en Teología, Universidad Católica de Lublin, en Polonia. Doctor en Derecho Canónico de la Pontificia Universidad Lateranense. Magíster en Teología de la Pontificia Academia de Teología, en Cracovia. Profesor en el Seminario Mayor de Grodno (Bielorrusia). Desde el 2004 trabaja en el Servicio Diplomático de la Santa Sede, Estado de la Ciudad del Vaticano.

Correo electrónico:

krydub07@gmail.com

Para citar este artículo: Dubiel, K. (2015). La privación de las exequias eclesiásticas en el Código de Derecho Canónico de 1983. Revista Civilizar Ciencias Sociales y Humanas, 15(28), 37-46. 


\section{Introducción}

Todas las civilizaciones y naciones han creado una imagen propia del evento de la muerte, que siempre ha sido la causa de honda reflexión en los diversos sistemas de las ciencias humanas. Sin embargo, el ser humano en su experiencia científica ha quedado humillado, porque aún no puede descubrir la respuesta suficiente (profunda) y explicar el misterio de su naturaleza mortal. La capacidad de entender y resolver este misterio se debate entre la muerte -como el final de la existencia humana sobre la tierra- y la inmortalidad del alma.

Entre muchos y diversos modos de expresar la experiencia humana de la muerte está la fe en la resurrección, profesada por los cristianos. El fundamento de esta fe es la resurrección de Jesucristo, que después de su óbito en la cruz resucitó. Este milagro y triunfo sobre la muerte y sobre satanás se convierte en el cimiento de la profesión de la fe en la vida eterna, que es el premio para aquellos que han vivido en la Tierra siguiendo y cumpliendo el Evangelio y han llevado su propia vida como discípulos de Jesucristo.

La iglesia enseña que el hombre fue creado para la vida eterna y que la muerte ha entrado en el mundo a causa de la culpa de este. Cristo, con su muerte y resurrección transformó el evento de la defunción del hombre: no más solo la pena por el pecado, sino el paso a la vida eterna. El día del fallecimiento para el cristiano es el día del cumplimiento de un nuevo nacimiento iniciado en el bautismo.

La iglesia, que se ocupa del peregrinar terreno de sus fieles, se encarga también de su cuidado en el momento de la expiración, ofreciendo sus oraciones a favor de la persona cuya vida terrena llega a su cumplimiento (término). El motivo de esta particular atención a los difuntos encuentra su soporte en la verdad de que el cuerpo humano es templo del Espíritu Santo. La iglesia intercede por aquellos que han dejado la vida: incorporados en la muerte y en la resurrección de Jesús entran en la vida eterna con todos los santos en la casa del Padre. Es por esto que la iglesia venera el cuerpo del difunto. La sepultura, como celebración litúrgica, debe expresar la verdad sobre la muerte, sobre la vida eterna y sobre la comunión de los santos. Todas estas verdades están iluminadas en la liturgia de la sepultura y en las oraciones fúnebres del funeral católico.

En la legislación canónica que regula la vida de la iglesia no podrían faltar las indicaciones que se refieren a este momento muy importante de la vida humana, que expresa la necesidad de llevar el cuerpo del difunto al lugar destinado a la sepultura y celebrar allá el rito de las exequias. En la legislación podemos distinguir una evolución de las disposiciones que reglan la sepultura eclesiástica. Dicha evolución se debe especialmente al progreso del concepto teológico de vida y de muerte y a la influencia de los ambientes científicos.

Este trabajo presenta solo un argumento de los que podemos encontrar en la rica parte de la legislación eclesiástica que atañe a la sepultura eclesiástica. La privación de las exequias eclesiásticas en el Código de Derecho Canónico -en latín Codex Iuris Canonici (CIC)- de 1983 es un tema muy interesante, en especial hoy que surgen diversas dudas sobre las circunstancias que llevan a la concesión o a la privación de la sepultura eclesiástica. El motivo que lleva a escoger esta problemática es la prueba que emana de recoger y presentar la documentación jurídica que puede ayudar a solucionar múltiples casos dudosos.

\section{Legislación actual de la iglesia sobre la sepultura en las disposiciones de las congregaciones}

El CIC de 1917 fue un evento trascendente en la vida de la iglesia católica. Las disposiciones que presentaba han sido de gran ayuda en la cura pastoral, disciplinaria y 
espiritual de los fieles. También la legislación, referente a la sepultura eclesiástica, se recogió en un capítulo que daba la posibilidad de aplicarla a las diferentes circunstancias de la vida. Empero, con el correr del tiempo y con el mismo desarrollo de las ciencias, el CIC de 1917 no era suficiente. Debido al surgimiento de algunas perplejidades frente a las distintas situaciones de la vida humana y también a problemas con la aplicación del derecho a la sepultura, se vio la necesidad de adaptar la legislación canónica a los distintos eventos $\mathrm{y}$, mediante las respuestas a las preguntas sobre los oficios competentes, resolver cada duda.

La viva actividad de las congregaciones de la Santa Sede comienza después del Concilio Vaticano II, que se fundó sobre el principio de actualización del magisterio eclesiástico. Las funciones de las congregaciones han sido de gran valor para la justa y responsable implementación del derecho en la vida cotidiana y ha reconocido el Código como un instrumento muy significativo en la vida de la iglesia. Acerca de la producción jurídica posterior al CIC de 1917, es menester considerar sobre todo tres decretos que han aclarado e incluso han innovado las disposiciones de este sobre la exclusión de la sepultura eclesiástica.

\section{El decreto del Santo Oficio de 1949.}

El decreto del Santo Oficio del 1 de julio de 1949, aunque no cita la sepultura eclesiástica, ha dado lugar a erróneas interpretaciones en torno a esta última. Este prevé tres preguntas:

1. Si es lícito inscribirse o favorecer al Partido Comunista.

2. Si es lícito leer, divulgar libros, periódicos, diarios y hojas que proclaman la doctrina y las actividades del comunismo.

3. Si los fieles que profesan la doctrina materialista o anticristiana del comu- nismo, y especialmente aquellos que lo defienden o lo propagan, incurren en la excomunión como apóstatas (Marantonio-Sguerzo, 1976).

A los fieles que en su actividad política están calificados dentro de los dos primeros puntos y lo hacen consciente y libremente, deben negárseles los sacramentos según los principios ordinarios. En cuanto a la tercera premisa, la de los fieles que incurran en la excomunión del cann. 2314 de $1917 \S 1$, podemos basar la explicación de la privación de las exequias sobre las disposiciones del decreto.

El punto central es que los fieles que pertenecen a los dos primeros grupos descritos en el decreto son excluidos de los sacramentos, pero esto no se hace en el caso de la sepultura, porque el cann. 1240 de 1983 no dice nada (Marantonio-Sguerzo, 1976, p. 183). En este caso se aplica el principio nullum crimen sine praevia lege poenali. Nos falta examinar el tercer punto, que reconoce a los fieles con esta cualidad del comportamiento como excomulgados Omnes a christiana fide apostatae et omnes et singuli haeretici aut schismatici (c.f. Cann. 2314 de 1917 § 1):

\section{$1^{\circ}$. Incurrunt ipso facto excommunicatio- nem;}

$2^{\circ}$. Nisi moniti resipuerint, priventur beneficio, dignitate, pensione, officio aliove munere, si quod in Ecclesia habant, infames declarentur, et clerici, iterata monitione, deponantur;

$3^{\circ}$. Si sectae acatholicae nomen dederint vel publice adhaeserint, ipso facto infames sunt et, firmo praescripto Cann. 188, n. 4, clerici, monitione incassum praemissa, degradentur.

La privación se apoya en la declaración de la excomunión mediante una sentencia declaratoria o condenatoria. En los otros 
casos de la pertenencia política y actividad en el Partido Comunista se le reconoce como miembro de la secta o herético y no se aplica la privación de la sepultura (Mauro, 1957, pp. 463-467).

\section{La instrucción De cadaverum cre- matione: piam et constantem.}

La reforma conciliar pretendía renovar toda la legislación precedente, las disposiciones respecto a las sanciones contenidas en el ordenamiento de la iglesia $\mathrm{y}$, de manera particular, por cuanto nos interesa, la sepultura eclesiástica; y efectivamente ha conducido a una revitalización del CIC de 1917 y llegando al CIC de 1983 a horizontes bastante innovadores en cuanto a la disciplina anterior. Un paso significativo en la evolución de la legislación eclesiástica es la instrucción de la Congregación del Santo Oficio (1963, pp. 822-823) De cadaverum crematione: piam et constantem. El breve texto, después de una premisa, concluye con una parte más normativa. Podemos distinguir los pasajes esenciales de él.

La incineración de cadáveres, como no toca el alma y no impide la omnipotencia divina de reconstruir el cuerpo, no contiene, en sí y por sí, la objetiva negación de estos dogmas. No se trata entonces de algo intrínsecamente malo o de por sí contrario a la religión cristiana; además, por el hecho de que en particulares circunstancias, en especial de orden público, la cremación estaba permitida. En la actualidad, siempre con mayor frecuencia, la cremación se pide por razones higiénicas, económicas o de otro género, de orden público o privado (Suchecki, 1995, pp. 167-169).

Sea fielmente mantenida la tradición de sepultar los cadáveres de los fieles, no se acuda al uso de la inhumación si no es en caso de verdadera necesidad (Cann. 1176 de 1983 § 3; Miragoli, 1996, p. 347). Los cánones 1203 y 1240 § 1, n. 5 de 1983 deben aplicarse solo cuando la cremación es querida como expresión de la negación de los dogmas cristianos o por odio contra la religión católica y la iglesia (Marantonio-Sguerzo, 1976, p. 185). Para no debilitar la adhesión del pueblo cristiano a la tradición eclesiástica y para mostrar la aversión de la iglesia por la cremación, los ritos de la sepultura eclesiástica y los subsiguientes sufragios no se celebrarán nunca en el lugar de la cremación y tampoco se acompañará el cadáver (Michałek, 1974, p.17).

\section{El decreto "La sepultura eclesiásti- ca de 1973".}

En los preceptos de este documento podemos distinguir dos puntos muy importantes. Primero declara que no se prohíban las exequias a los pecadores manifiestos, si antes de la muerte dieron algún signo de penitencia. Segundo se refiere al peligro de eventual escándalo de otros fieles (Marantonio-Sguerzo, 1976, p. 187). En consecuencia, las disposiciones del CIC de 1917, nombradas en el cann. 1240 de 1983 (§ 1, n. 5), no deben ya observarse. El nuevo decreto, que abroga el canon en mención, mitiga de modo notable la legislación, condiciona la concesión de la sepultura a cualquier signo de penitencia y que sea evitado el escándalo (Suchecki, 1995, pp. 188-189).

La privación de las exequias es impuesta y está destinada en primer lugar a reparar el escándalo provocado por algunos pecadores con su comportamiento y, en segundo lugar, a amonestar los sobrevivientes para que no sigan aquel ejemplo y a sanar la propia fe (Vitale, 1964, pp. 150-151). La decisión del legislador en las diversas innovaciones del derecho que alude a la sepultura, sigue la finalidad de la salus animarum, y da siempre la posibilidad para la conversión y la reconciliación (Decreto sulla sepoltura ecclesiastica di 1973).

\section{La privación de las exequias eclesiásticas en el Código de Derecho Canónico de 1983}

Antes de analizar los cánones del CIC de 1983 debemos subrayar que para la formación 
de los cánones que regulan la sepultura han tenido influencia dos documentos. Primero, la instrucción De cadaverum crematione: piam et constantem (Congregación del Santo Oficio, 1963), cuyo contenido hemos visto en el primer parágrafo. Segundo, el Ordo exsequiarum, que se publicó el 15 de agosto de 1969. En este documento distinguimos el decreto de la promulgación de la congregación del culto divino, las premisas y ocho capítulos que tratan respectivamente de la vigilia en la casa del difunto y la colocación del féretro del cuerpo del difunto (c. I); los tres tipos de exequias (c. II, II, IV); las exequias de los niños (c. V); y una antología de lecturas bíblicas, salmos, oraciones y responsorios para utilizar en las exequias de los adultos y de los niños (c. VI, VII, VIII) (Oggini, 1975, p. 3).

El punto de partida de la renovación del rito del funeral cristiano es el programa trazado por el Concilio Vaticano II, principalmente en la constitución Sacrosanctum Concilium, $\mathrm{y}$ en particular lo dispuesto en la misma en los numerales 81-82. "El rito de las exequias exprese más abiertamente la dimensión pascual de la muerte cristiana y responda mejor, también en cuanto al color litúrgico, a las condiciones y a las tradiciones de las regiones particulares"; "revísese el rito de la sepultura de niños, dotándose de una misa propia" (Bondioli, 1968, p. 318).

De estos dos numerales de la constitución resultan dos orientaciones generales -expresar mejor el misterio pascual y adaptar el rito a las diversas situaciones y tradiciones- $\mathrm{y}$ dos prescripciones particulares: mayor idoneidad del color litúrgico y creación de una misa propia para la sepultura de los niños. En el texto encontramos tres criterios fundamentales de la reforma. Al inicio surge el consejo de una mejor expresión del misterio pascual,

[...] la liturgia cristiana presente en el funeral es una celebración del misterio pascual de Cristo el Señor [...] La iglesia ruega que sus hijos incorporados por el bautismo a Cristo muerto y resucitado pasen con Él de la muerte a la vida $[\ldots]$ y ofrece por los difuntos el sacrificio eucarístico, memorial de la pascua de Cristo (Rituale Romanum, 1969. n. 1 (EV 3/1437)).

Con base en este criterio el nuevo rito del funeral se sitúa en el surco de la más auténtica tradición de la liturgia funeraria de la iglesia latina. Coloca en un relieve particular la conexión de la muerte del cristiano con la pascua de Cristo, poniendo en posición secundaria la oración de sufragio y de purificación del difunto; pretende redescubrir la esperanza de los vivos, ayudarles a confesar su propia fe en la victoria de Cristo sobre la muerte y consolar su dolor (Mazzariello, 1968, p. 297). Ofrece, además, una celebración animada por un sentido de serenidad y de alegría, que se soporta en la certeza de la comunidad de los creyentes de participar en la pascua del hermano difunto, "su liberación del exilio", su ingreso en la casa del Padre (Lodi, 1971, p. 344).

El segundo punto sobre la reflexión y la renovación del rito de la sepultura eclesiástica propone una justa adaptación de la celebración a las situaciones y tradiciones concretas. Este criterio es sugerido por la actual difusión de la iglesia en los pueblos y civilizaciones profundamente diversas, por el notable cambio de mentalidad que presencia el mundo, en fin, por el nuevo modo de sentir algunos aspectos del problema de la muerte (Gozzelino, 1971, p. 305).

En específico recordamos, en orden a esta exigencia de adaptación, la hipersensibilidad de muchos contemporáneos delante de la muerte y a todo lo que con ella se relaciona, según el pensamiento cristiano: juicio divino, posibilidad de una condenación eterna. La consecuente necesidad de un lenguaje más adecuado y de una particular atención al modo de expresarse; la coexistencia de usos regionales bastante diversos que se pueden reducir a tres grandes tipos, dependiendo de si la acción litúrgica principal tiene lugar en la iglesia, o en el cementerio, o en la casa del difunto (Lodi, 1972, p. 202). La 
progresiva urbanización tiende a favorecer las exequias en el cementerio, incluso cuanto estas tienen lugar en la iglesia, y ha hecho decaer el cortejo fúnebre y las situaciones litúrgicas en la casa del difunto y el cementerio (Falsini, 1972, p. 214).

El tercer criterio se refiere a la sensibilidad del grado de vida cristiana, a las actitudes y a las características concretas de los familiares del difunto y de aquellos que participan en la celebración. El nuevo rito, además, es particularmente atento no solo al acontecimiento del difunto, sino también a la comunidad que oficia las exequias con una aguda preocupación de evangelización y de catequesis (Gozzelino, 1971, p. 307).

"El Ordo exsequiarum ha cambiado la decisión del decreto De cadaverum crematione: piam et constantem" (Congregación del Santo Oficio, 1963) que prohibía la celebración del rito funerario en el crematorio. Desde el momento de su promulgación se pueden consagrar las oraciones en el lugar de la cremación, y se puede acompañar allí al difunto (Michełek, 1974, p. 17).

En el nuevo rito no se dice nada acerca de la privación de la sepultura. Este deja el argumento al CIC (1983), que en el cann. 1184 de 1983 §1 enumera los casos de la exclusión. Con las disposiciones del cann. 1184 de 1983 $\S 1$, que presenta las categorías de las personas privadas de la sepultura, debemos resaltar una condición de la cual depende la aplicación del mencionado canon.

Si antes de la muerte no dieron algún signo de arrepentimiento deben ser privados de las exequias eclesiásticas:

$1^{\circ}$ los notoriamente apóstatas, herejes, cismáticos;

$2^{\circ}$ aquellos que eligieron la cremación del propio cuerpo por razones contrarias a la fe cristiana; $3^{\circ}$ los otros pecadores manifiestos, a quienes no es posible conceder las exequias sin público escándalo de los fieles.

El legislador funda su decisión de excluir a ciertas personas de la sepultura si falta un verdadero signo de arrepentimiento y reconciliación (Jassoni, 1988, pp. 869-872). Estos casos que indican una verdadera y propia voluntad del difunto de pedir el perdón los hemos visto en el capítulo segundo, referente a las disposiciones del CIC de 1917, en que el moribundo besa el crucifijo o ha pedido la confesión. Los apóstatas, los heréticos y los cismáticos notorios, no aquellos ocultos que no lo son con certeza.

La notoriedad puede ser de derecho, si los casos citados resultan de una sentencia judicial o de una declaración oficial de la autoridad eclesiástica, y puede ser de hecho cuando el reo y su comportamiento son del todo conocidos (Cann. 1311 de 1983; Cann 1362 de 1983; Suchekki, 1995, pp. 56-62). En la ocasión del juicio de la posición de los cismáticos, de los apóstatas y de los heréticos encontramos la disposición del legislador, que se puede conceder las exequias eclesiásticas a los bautizados inscritos en una iglesia o comunidad eclesial no católica (Cann. 1183 de 1983 § 3). Para realizar está posibilidad del Código deben existir las siguientes condiciones:

- $\quad$ El permiso del ordinario del lugar.

- Que no conste de la voluntad contraria.

- Que en el mismo tiempo, no sea posible tener un ministro propio.

La cremación se ha convertido en causa de la exclusión solo en el caso de la motivación que es contraria a la doctrina eclesial (Cann. 1176 de $1983 \S 3$ ); en otros casos no se prohíbe. Aquí podemos ver que la iglesia otorga tanta confianza a sus creyentes, reconoce su propia responsabilidad y madurez en la fe (Gutiérrez, 
1995, pp. 183-184). A los otros pecadores manifiestos -concubinos públicos, quienes se adhieren de manera notoria a ideologías materialistas $\mathrm{y}$ ateas $\mathrm{y}$ los inscritos en asociaciones contrarias a la iglesia- (Chiappetta, 1994, p. 878), no es posible concederles la sepultura sin provocar un escándalo público entre los fieles.

En este caso de los pecadores públicos, los heréticos y cismáticos y los apóstatas no basta el signo del arrepentimiento, sino que se debe considerar el peligro de escándalo (Chiappetta, 1996, p. 308). Según esta disposición del CIC de 1983, queda clara la aplicación del decreto "La sepultura eclesiástica” de 1973. El escándalo se puede evitar escogiendo una forma de funeral más simple, sin grandes celebraciones que han sido propuestas en el nuevo Ordo exsequiarum (Marchesi, 1992, p. 310).

Siempre queda la posibilidad de dirigirse al ordinario cuando surja alguna duda respecto a la aplicación de la norma jurídica (cann. 1184 de 1983 § 2). La privación de las exequias eclesiásticas conlleva coherentemente la negación de cualquier misa exequial, es decir, de misas oficiadas públicamente con ocasión de las exequias. Esto no impide que, en tal caso, se celebren en privado misas en sufragio del difunto, que tiene tanta necesidad de la misericordia de Dios (cann. 1185 de 1983; Chiappetta, 1996, p. 308).

El nuevo Código omite en absoluto el problema de la exclusión por causa del suicidio. Según la opinión de psicólogos y psiquiatras, estas personas no son con plenitud responsables por los actos que cometen. Si eran católicos practicantes y no demostraron antes de morir un comportamiento escandaloso no se les niega el funeral católico(Janczewski, 1917, pp. 136-137).

Muy significativa es la decisión del legislador que permite que se oficien las exequias de los niños muertos sin bautizar, si los padres tenían la intención de bautizarlos (Cann.
1183 de 1983 § 2). Es necesario el permiso del ordinario, el cual debe constatar la real intención de los padres si el bautismo no fue descuidado (Sztafrowski, 1986, pp. 202-203). El CIC de 1983 no cambia nada acerca de las disposiciones del Código anterior sobre la sepultura de los catecúmenos; ellos se equiparan a los bautizados sobre la base de un vínculo particular con Cristo y también se presume el deseo del bautismo (Chiappetta, 1996, p. 308). La eventual decisión de la privación de la sepultura eclesiástica no puede ser un acto de venganza del párroco que ha tenido algún problema con la familia del difunto o con él mismo, al contrario debe consolar al hogar que se encuentra de luto (Marchesi, 1992, pp. 312-313).

La legislación canónica que se ha presentado tuvo siempre el objetivo de ayudar a solucionar diversos problemas que surgen en los distintos momentos de la vida de la iglesia: adaptar el derecho a la vida de una manera más perfecta y reavivar la devoción de los fieles y fundarla sobre la fe en la resurrección. Sobre esto aparecen ejemplos de ecumenismo. Se otorga la confianza a los fieles que optan por la cremación, no por causa de la negación de los dogmas eclesiásticos, solo como solución más práctica o económica. Las variaciones del derecho de la sepultura eclesiástica han dado origen a celebraciones más fáciles para los familiares que se encuentran en situaciones difíciles después de la desaparición de sus seres queridos.

\section{Conclusiones}

Para la iglesia la institución de la sepultura fue siempre importante. Esto lo vemos en la liturgia de las exequias, donde se expresa la fe en la resurrección, en la vida eterna y en la veneración del cuerpo humano. Este trabajo ilustró las disposiciones de la legislación canónica que llevan a la privación de la sepultura eclesiástica. Las decisiones que excluyen a la persona del difunto de la posibilidad de la celebración exequial se soportan en el contenido 
del cann. 1184 de $1983 \S 1$, que enumera las categorías de los excluidos.

Para una mejor explicación del argumento ha sido necesario ver la historia de la institución de las exequias y las disposiciones jurídicas que condujeron al establecimiento de la sepultura eclesiástica vigente. La primera conclusión de la nueva legislación canónica que está vigente en la iglesia tiene confianza en la fe de sus miembros, en el caso de la cremación. Por lo tanto, la cremación reconoce la voluntad de los creyentes que la escogieron no como contraria a los dogmas de la vida eterna.

Podemos ver que el legislador acepta la solución del problema del espacio y de la higiene en el caso de la sepultura. La legislación vigente disminuyó la lista de las categorías de personas privadas de la sepultura respecto al Código de 1917. Cambia el sentido de la privación que no tiene nunca un carácter de pena (castigo), sino solo de extrema ratio como la consecuencia de la opción hecha antes de la muerte. Muy relevante es la disposición que subraya el gesto del arrepentimiento del difunto demostrado antes de la muerte que permite la celebración de las exequias. El mencionado motivo resuelve muchas dudas que pueden encontrar los pastores en su misión en la iglesia católica. Siempre está vigente la cláusula que indica la necesidad de evitar un escándalo entre los fieles.

\section{Referencias}

Bondioli, D. (1968). Ad ogni funerale la sua celebrazione liturgica. Rivista di Pastorali Liturgica, 6.

Cann. 2314 de $1917 \S 1$. Todos los apóstatas de la fe cristiana y todos y cada uno de los herejes o cismáticos: 1) incurren ipso facto ["en el acto" o "inmediatamente"] en excomunión [...]. Código de derecho canónico. Iglesia Católica Romana, agosto de 1917.
Cann. 1176 de $1983 \S 3$. De las exequias eclesiásticas. La Iglesia aconseja vivamente que se conserve la piadosa costumbre de sepultar el cadáver de los difuntos; sin embargo, no prohíbe la cremación, a no ser que haya sido elegida por razones contrarias a la doctrina cristiana. Código de derecho canónico. Iglesia Católica Romana, enero de 1983.

Cann. 1183 de $1983 \S 2$. De aquellos a quienes se ha de conceder o denegar las exequias eclesiásticas. El Ordinario del lugar puede permitir que se celebren exequias eclesiásticas por aquellos niños que sus padres deseaban bautizar, pero murieron antes de recibir el bautismo. Código de derecho canónico, Iglesia Católica Romana, enero de 1983.

Cann. 1183 de 1983 § 3. De aquellos a quienes se ha de conceder o denegar las exequias eclesiásticas. Según el juicio prudente del Ordinario del lugar, se pueden conceder exequias eclesiásticas a los bautizados que estaban adscritos a una Iglesia o comunidad eclesial no católica, con tal de que no conste la voluntad contraria de éstos, y no pueda hacerlas su ministro propio. Código de derecho canónico, Iglesia Católica Romana, enero de 1983.

Cann. 1184 de $1983 \S 1$. Se han de negar las exequias eclesiásticas, a no ser que antes de la muerte hubieran dado alguna señal de arrepentimiento: A los notoriamente apóstatas, herejes o cismáticos. A los que pidieron la cremación de su cadáver por razones contrarias a la fe cristiana. Código de derecho canónico. Iglesia católica Romana, enero de 1983.

Cann. 1184 de $1983 \S 2$. En el caso de que surja alguna duda, hay que consultar al Ordinario del lugar y atenerse a sus disposiciones. Código de derecho canónico. Iglesia católica Romana, enero de 1983. 
Cann. 1185 de 1983. A quien ha sido excluido de las exequias eclesiásticas se le negará también cualquier Misa exequial. Código de derecho canónico. Iglesia Católica Romana, enero de 1983.

Cann. 1203 de 1983. Del juramento. Quienes tienen potestad para suspender, dispensar o conmutar un voto, gozan de la misma potestad y por igual razón respecto al juramento promisorio; pero si la dispensa del juramento redunda en perjuicio de otros que rehúsan condonar la obligación, sólo la Sede Apostólica puede dispensar de ese juramento. Código de derecho canónico. Iglesia Católica Romana, enero 1983.

Cann. 1240 de $1983 \S 1$. De los cementerios. Donde sea posible, la Iglesia debe tener cementerios propios, o al menos un espacio en los cementerios civiles bendecido debidamente, destinado a la sepultura de los fieles. Código de derecho canónico. Iglesia católica Romana, enero de 1983.

Cann. 1311 de 1983. De los delitos y penas en general. La Iglesia tiene derecho originario y propio a castigar con sanciones penales a los fieles que cometen delitos. Código de derecho Canónico. Iglesia católica Romana, enero de 1983.

Cann. 1362 de 1983. La acción criminal se extingue por prescripción a los tres años, a no ser que se trate: 1 . De los delitos reservados a la Congregación para la Doctrina de la Fe; 2. De la acción por los delitos de los que se trata en los cánones 1394, 1395,1397 y 1398 , la cual prescribe a los cinco años; 3 . De los delitos que no se castigan por el derecho común, si la ley particular determina otro plazo para la prescripción. 3.1) El tiempo para la prescripción comienza a contarse a partir del día en el que se cometió el delito, o, cuando se trata de un delito continuado o habitual, a partir del día en que cesó.
Código de derecho canónico. Iglesia Católica Romana, enero de 1983.

Catholic Church. (1969). Ordo Exsequiarum. Rituale Romanum ex decreto Sacrosancti Oecumenici Concilii Vaticani II instauratum. Roma: Typis Polyglottis Vaticanis.

Chiappetta, L. (1994). Prontuario di diritto canonico e concordatario. Roma: Edizioni Dehoniane.

Chiappetta, L . (1996). Il Codice diritto canonico. Commento giuridico-pastorale. Roma: Edizioni Dehoniane.

Congregación del Santo Oficio- [S.C.S. Off]. (1963). De cadaverum crematione: piam et constantem. $A A S, 56,822-823$.

Decreto del S. Oficio (1-07-1949), AAS (1941), 41.

Decreto sulla sepoltura ecclesiastica di 1973. Circa la sepoltura ecclesiastica hanno decretato che non siano più vietate le esequie ai peccatori manifesti, se prima della morte hanno dato qualche segno di penitenza e se è evitato il pubblico scandalo degli altri fedeli. Sacra Congregazione per la Dottrina della Fede AAS 65, settembre di 1973.

Falsini, R. (1972). Nota sulla rinnovata liturgia dei defunti. Rivista di Pastorali Liturgica, 10.

Gozzelino, G. (1971). Il nuovo rito delle esequie e la teologia contemporanea della morte. Rivista Liturgica, 38.

Gutiérrez, J. L. (1995). Gli altri atti del culto divino (cann., 1166-1204). En Gruppo Italiano Docenti di Diritto Canonico, $\mathrm{La}$ funzione di santificare della Chiesa (pp. 179-191). Milan: Glossa.

Jassoni, M. (1988). La nuova disciplina del diniego della sepoltura ecclesiastica. En 
Studi in memoria di M. Condorelli (Vols. 1-2), Milano: Giuffrè.

Janczewski, Z. (1917). Ewolucja przepisów dotyczacych pogrzebu koscielnego od Kodeksu Prawa Kanonicznego z, roku. Prawo Kanoniczne, 1(2), 123-140.

Lodi, E. (1971). La pastorale del nuovo rito delle esequie. Rivista Liturgica, 38.

Lodi, E . (1972). La visione della morte e dei suffragi nell'Ordo Exequiarum. Rivista di Pastorale Liturgica, 10, 201-211.

Marantonio-Sguerzo, E. (1976). Evoluzione storico-giuridica dell'istituto della sepoltura ecclesiastica. Milán:Universita' degli studi di genova pubblicazioni dell'istituto di studi storico - politici facolta' di scienze politiche.

Marchesi, M. (1992). Gli altri atti del culto divino. En Gruppo Italiano Docenti Di Diritto Canonico (Ed.), Il diritto nel mistero della Chiesa (Vol 3). Roma: Laterano University Press.

Mauro, T. (1957). Poteri dei ministri di culto in materia sacramentale e art. 599 C. p. II Diritto Ecclesiastico, 4, 425-486.
Mazzariello, S. (1968). La struttura del nuovo rito dei funerali. Rivista di Pastorale Liturgica, 6, 298-313.

Michałek, R. (1974). Nowe obrzedy pogrzebu $i$ zwiazane z nim poroblemy prawno liturgiczne, 27.

Miragoli, E. (1996). La cremazione del corpo dei defunti (can., 1176 §3). Quaderni di Diritto Ecclesiale, 9, 337-356.

Oggini, C. (1975). Il nuovo rito dei funerali. Rivista di Pastorale Liturgica, 71.

Suchecki, Z. (1995). La cremazione del diritto canonico e civile. Ciudad del Vaticano: Libreria Editrice Vaticana.

Suchecki, Z. (1999). Le sanzioni penali nella Chiesa, Parte I, I delitti e le sanzioni penali in genere (cann., 1311-1362). Ciudad del Vaticano: Libreria Editrice Vaticana.

Sztafrowski, E. (1986). Podrecznik Prawa Kanonicznego (Tomo. 4). Warzawa:Akademia Teologii Katolickiej.

Vitale, A. (1964). Contributo ad una teoria delle sanzioni nell'ordinamento canonico. Ephemerides Iuris Canonici, 20. 